\title{
ARTICLE
}

\section{Long-term radiation impact of conditionally cleared radioactive material from decommissioning of nuclear power plants reused in building industry}

\author{
Michal Panik* and Vladimir Necas \\ Slovak University of Technology in Bratislava, Ilkovicova 3, 812 19, Bratislava, Slovakia
}

\begin{abstract}
In the process of decommissioning of nuclear facilities there is produced a lot of material with various levels of radioactivity. Large portion of the material could be conditionally cleared as an alternative to the treatment and disposal of this material as radioactive waste. Idea of conditional clearance is to facilitate the reuse of material with the radioactivity slightly above legislation limits of specific activity valid for unconditional clearance into the environment keeping dose criteria for the public. The radiation impact of cleared materials can be divided into short-term and long-term impact. Long-term radiation impact consists of inhalation or ingestion of radionuclides and external irradiation from the contaminated soil or dust. Transport of radionuclides from the conditionally cleared materials through the subsoil or waterways and subsequent intake of these radionuclides by humans was simulated and calculated using GOLDSIM software. Calculated models represent situations and geometries of the most probable future applications of conditionally cleared materials in building constructions. Output parameters are the clearance levels of radionuclides in conditionally cleared materials relevant to the legislation dose criteria $(10$ or $50 \mu \mathrm{Sv} / \mathrm{year})$ - the maximum clearable specific activity of radionuclides in the material from the dose point of view.
\end{abstract}

Keywords: conditional clearance; decommissioning; GOLDSIM; exposure pathway; long-term radiation impact; recycling

\section{Introduction}

Very low level radioactive materials produced during decommissioning of nuclear installations (NI) that fulfill criteria for clearance into the environment can be cleared unconditionally or conditionally. Possible safety threats and resulting strict specific activity limits of unconditional release are determined by studies expecting "worst case scenario" of utilization of cleared material. Conditional clearance concept demands utilization of cleared material for previously defined purpose (i.e. building constructions). This concept practically ensures that specific activity of cleared materials can be higher than the limits for unconditional clearance and therefore the amount of cleared material can increase. Considering the number of NI under decommissioning in the world, the increase of recycling of waste materials is advantageous not only for nuclear industry. Short-term and long-term safety of conditional clearance and utilization of materials for specified purpose have to be proven by case study. This paper deals with long-term radiation impact of application of conditionally cleared concrete rubble and carbon steel in various building constructions. The impact was modeled and calculated in computational tool GOLDSIM [1].

*Corresponding author. Email: michal.panik@stuba.sk

\section{Method}

Methodology of long-term environmental impact assessment of application of conditionally cleared materials was taken from the area of radioactive waste disposal and modified to comply with the different requirements. In this paper, there is an intention to cover the long-term impact of the set of most probable building applications of conditionally cleared materials. Examination of long-term impact begins at the end of lifespan of construction (usually 100 years) and it ends after dose from all considered radionuclides reach its maximum (10 000 years). Used methodology and results of calculations should provide an overview of impact of conditionally cleared materials on the health of inhabitants in the large time scale.

The most important parameter for the safety assessment of conditional clearance concept is the criterion of annual individual effective dose. International documents [2] recommend the value of this parameter as "few tens of $\mu \mathrm{Sv}$ per year". Slovak legislation requires exact level of $10 \mu \mathrm{Sv} / \mathrm{yr}$ or $50 \mu \mathrm{Sv} / \mathrm{yr}$ after proving that chosen application is optimal from the radiation protection point of view.

\subsection{Output parameters of calculations}

Output parameters of calculations comprise 
individual effective doses of inhabitants living near the finished construction. Calculated doses compared to dose criteria from legislation are than used for determination of recalculated "clearance levels" (CL) valid for specific construction. CLs are maximum values of mass specific activities of radionuclides in cleared material applicable without exceeding the dose criteria. The derivation of the $\mathrm{CL}$ of radionuclide is performed by using following Eq. (1):

$$
a=\frac{D_{L}}{I E D} a_{u}
$$

where: a - derived clearance level $[\mathrm{Bq} / \mathrm{kg}]$,

$\mathrm{DL}-$ dose criterion $(10 \mu \mathrm{Sv} / \mathrm{yr}$ or $50 \mu \mathrm{Sv} / \mathrm{yr})$,

IED - calculated annual individual effective dose received by critical individual [Sv/yr],

$\mathrm{a}_{\mathrm{u}}$ - input value of specific mass activity $[\mathrm{Bq} / \mathrm{kg}]$.

Next output parameter is identification of 'critical' exposure pathway for each radionuclide - pathway that results in highest received dose.

\subsection{Scenarios of conditional clearance - Conceptual models}

It is necessary to create a conceptual model for each significantly different scenario. Radiation source in each scenario consists of radionuclides chosen according to international document [3] and radiological characterization of Slovak nuclear power plants that are currently under decommissioning. Values of output parameters must be obtained separately for each radionuclide, thus the source of radiation can be considered "single nuclide" for each realization of calculations. Considered exposure pathways are following:

- External irradiation

- Inhalation

- Ingestion

In case of application of calculated CLs on radionuclide vector (mixture of radionuclides with specified ratios between them) of selected NI, it is needed to modify the CL of each radionuclide of the vector based on Eq. (2):

$$
\sum_{i=1}^{n} \frac{c_{i}}{c_{L i}} \leq 1,0
$$

where: $c_{i}-$ mass specific activity of radionuclide $i$ in mixture $[\mathrm{Bq} / \mathrm{kg}]$;

$\mathrm{c}_{\mathrm{Li}}$ - clearance level of radionuclide $\mathrm{i}[\mathrm{Bq} / \mathrm{kg}]$;

$\mathrm{n}$ - number of radionuclides in mix [-].

Near field is represented by the form of conditionally cleared material that fixes radionuclides in its internal structure. Specifically, the form of concrete rubble is concrete grit when utilized for road construction. Steel scrap can be utilized in form of reinforcing rods or other products, thus the form of material is smelted carbon steel. Another barrier for release of radionuclides is material/matrix that incorporates conditionally cleared material. This barrier is applied only in case of reinforced concrete constructions where reinforcing steel rods are covered by concrete. Natural barrier in near field is represented by geological environment, in model cases specifically sandy soil due to its high permeability. Dimensions of near field depends on the input parameters of modeled scenario, but generally the distance between examined source material (steel or concrete grit) and the outer boundary of near field do not exceed $10 \mathrm{~m}$.

After the release of radionuclides from conditionally cleared materials through all barriers included in near field, they reach the geosphere. In model cases, geosphere - far field is formed by layer of clay soil where groundwater flows. Groundwater washes radionuclides away to biosphere. These radionuclides can migrate to the well which is a source of potable and irrigation water. Situation is shown in Figure 1. Dimensions of far field reach tens of meters depending on modeled scenario.

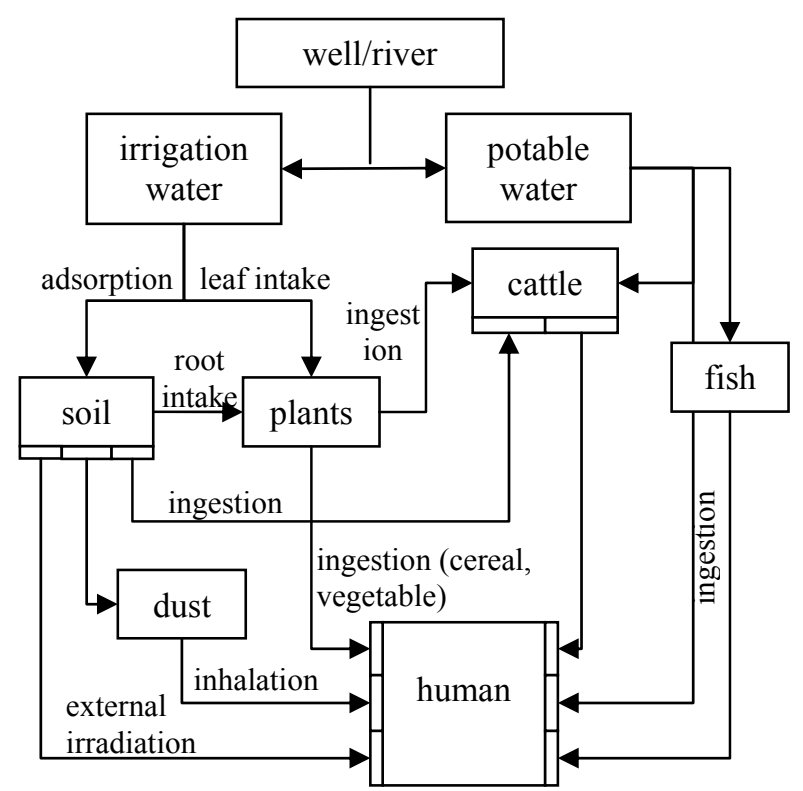

Figure 1. Scheme of modeled biosphere [3].

Scenarios of long-term impact of conditional clearance of materials can be divided based on type of material and based on type of building construction, where this material can be utilized. Using this logic, following 6 scenarios were created:

S1 - The road

$\mathbf{S} \mathbf{2}$ - The aboveground reinforced concrete construction

S3 - The underground reinforced concrete construction

$\mathbf{S} 4$ - The aboveground steel construction

S5 - The underground steel construction

S6 - The tunnel

\subsubsection{The Scenario S1- The road}

Utilization of contaminated concrete rubble from decommissioning of NI as a material of base layer of the road is considered in the Scenario S1. The covering layer above concrete base is made of asphalt which degrades and thus increases the rate of penetrated rainwater during its lifetime. Rainwater penetrating through the covering asphalt layer slowly dissolves the matrix (concrete) where radionuclides are incorporated 
and these radionuclides are then washed away by water through the unsaturated layer into the saturated layer. Then radionuclides are carried away by groundwater into the well used as source of drinking and irrigation water. Radionuclides are divided between solid and liquid phase according to the distribution coefficients. Advection and dispersion process of transport of radionuclides is considered in the model. Diffusion is ignored because this process is minor in comparison with advection in environments with other then very low hydraulic conductivity. When the contaminated water reaches the uncontaminated groundwater, mixing of these waters occurs and concentration of radionuclides decreases. Darcy velocity of groundwater influences mixing of water. The studied parameter is the concentration of radionuclides in the water from well. The concentration represents basis for the calculation of doses of radiation from all considered exposure pathways.

\subsubsection{The Scenario S2 - Aboveground reinforced concrete construction}

In Scenario S2 conditionally cleared carbon steel is used as reinforcement of concrete construction. Example of such construction is aboveground part of concrete reinforced bridge. The covering concrete layer that protects steel reinforcement from the external environment (rainfall influence, etc.) degrades. Then the steel reinforcement starts to corrode and the corrosion products slough from the surface of material or they can be washed away by rainwater until they reach the soil under the construction. Following radionuclide transport process is similar to Scenario S1. Conceptual model of Scenario S2 is illustrated at Figure 2.

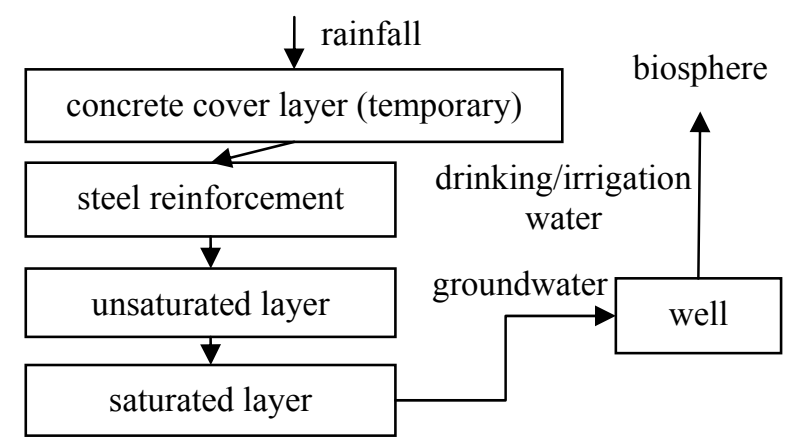

Figure 2. Conceptual model scheme of Scenario S2.

\subsubsection{The Scenario S3 - Underground reinforced concrete construction}

In Scenario S3 conditionally cleared carbon steel is used as reinforcement of the foundation of the concrete construction. Example of such construction is underground piles of concrete bridge or flood barrier. The concrete cover layer separating steel reinforcements from the saturated zone degrades because of soil and groundwater chemistry. Reinforcement steel will be "entombed" in concrete for specified duration and the processes of corrosion or decrease of thickness of the material will not occur during this time. After that, the reinforcing steel starts to corrode and the thickness of material decreases. Following radionuclide transport process is similar to Scenario $\mathrm{S} 1$. The conceptual scheme of model of Scenario S3 is the same as scheme for the Scenario S2 (Figure 2).

\subsubsection{Scenario S4 - Aboveground steel construction}

In Scenario S4 conditionally cleared carbon steel is used in form of steel components with various dimensions and shapes. For example, such components can be used for construction of storage hall or steel railway bridge. The components of steel bridge were chosen as the basis for conceptual model of this scenario. The decrease of thickness of material is caused by corrosion. The rainfall containing corrosion products or directly small corroded fragments falls into the river. The river washes away radionuclides into lake. Water from the lake is used as drinking or irrigation water just like in Scenario S1 - S3. Moreover this water is used for breeding of fish that are later used as food. Conceptual model of Scenario S4 is depicted at Figure 3.

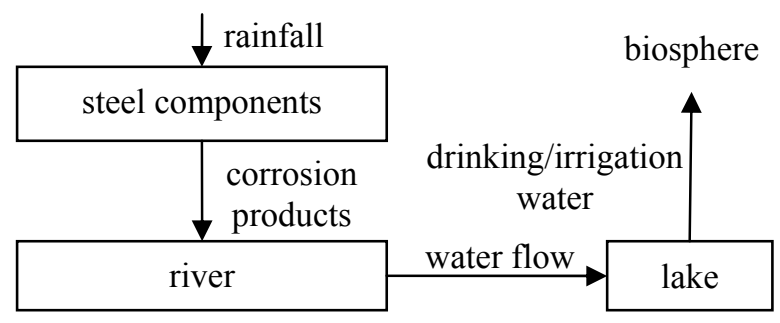

Figure 3. Conceptual model scheme of Scenario S4.

\subsubsection{Scenario S5 - Underground steel construction}

In Scenario S5 conditionally cleared carbon steel is used in form of components with various dimensions and shapes located under the ground. The examples from practice are sheet piles - steel components used for strengthening the hillsides to prevent the landslide. Such steel components do not have any anti-corrosion protection or cover layer therefore they start to corrode immediately after their insertion into the ground. Following radionuclide transport process is similar to Scenario S1.

\subsubsection{Scenario S6 - Tunnel}

In Scenario S6 conditionally cleared carbon steel is used as primary lining of tunnel. Reinforcement is in form of reinforcing mesh. The rainwater that flows through the massif layers gets directly to the tunnel lining, which represents natural barrier for water flow, because of its high hydraulic conductivity. Concrete cover layer protecting the reinforcement against corrosion is affected by penetrating water. Cover layer slowly degrades and the corrosion products are getting into water and then they are washed away. The water flowing around the tunnel lining is drained in drain pipe and it flows into the brook. Water from the brook is flowing into the pond. Water from this pond is used as drinking or irrigation water just like in Scenario S1 - S3 and S5. 


\section{Results and discussion}

Results of calculation of models of scenarios in GOLDSIM comprise parameters described in section 2.1. Input parameters needed for calculations were taken from international documents (sources of equations-[1],[4]; sources of data-[3-6]) and building practice. Results are only shown for selected radionuclides and Scenario S5 (as an example) (Table 1.) due to spatial limitations and clarity of results. Results of other scenarios are discussed later.

Table 1. Results of calculation (Scenario S5).

\begin{tabular}{|c|c|c|c|c|}
\hline \multirow{2}{*}{$\begin{array}{l}\text { Radio- } \\
\text { nuclide }\end{array}$} & \multirow{2}{*}{$\begin{array}{c}\text { Clearance } \\
\text { Level* }\end{array}$} & \multirow{2}{*}{$\begin{array}{l}\text { Critical } \\
\text { Exposure } \\
\text { Pathway }\end{array}$} & \multicolumn{2}{|c|}{$\begin{array}{c}\text { Clearance Level } \\
{[\mathrm{Bq} / \mathrm{kg}]}\end{array}$} \\
\hline & & & $10 \mu S v$ & $50 \mu S v$ \\
\hline $\mathrm{H}-3$ & $3.00 \mathrm{E}+06$ & Ingestion & $5.14 \mathrm{E}+08$ & $2.57 \mathrm{E}+09$ \\
\hline Be-10 & $3.00 \mathrm{E}+04$ & Ingestion & $6.84 \mathrm{E}+07$ & $3.42 \mathrm{E}+08$ \\
\hline C-14 & $3.00 \mathrm{E}+05$ & Ingestion & $8.60 \mathrm{E}+06$ & $4.30 \mathrm{E}+07$ \\
\hline $\mathrm{K}-40$ & $3.00 \mathrm{E}+03$ & Ingestion & $1.61 \mathrm{E}+06$ & $8.05 \mathrm{E}+06$ \\
\hline Ca-41 & $3.00 \mathrm{E}+05$ & Ingestion & $1.66 \mathrm{E}+07$ & $8.28 \mathrm{E}+07$ \\
\hline Ni-59 & $3.00 \mathrm{E}+05$ & Ingestion & $3.78 \mathrm{E}+08$ & $1.89 \mathrm{E}+09$ \\
\hline Co-60 & $3.00 \mathrm{E}+02$ & External & $8.30 \mathrm{E}+12$ & $4.15 E+13$ \\
\hline Ni-63 & $3.00 \mathrm{E}+06$ & Ingestion & $9.74 \mathrm{E}+09$ & $4.87 \mathrm{E}+10$ \\
\hline Se-79 & $3.00 \mathrm{E}+04$ & Ingestion & $5.69 \mathrm{E}+06$ & $2.84 \mathrm{E}+07$ \\
\hline Sr-90 & $3.00 \mathrm{E}+03$ & Ingestion & $1.29 \mathrm{E}+06$ & $6.44 \mathrm{E}+06$ \\
\hline Mo-93 & $3.00 \mathrm{E}+04$ & Ingestion & $5.10 \mathrm{E}+06$ & $2.55 \mathrm{E}+07$ \\
\hline Zr-93 & $3.00 \mathrm{E}+05$ & Inhalation & $7.01 \mathrm{E}+07$ & $3.50 \mathrm{E}+08$ \\
\hline $\mathrm{Nb}-93 \mathrm{~m}$ & $3.00 \mathrm{E}+04$ & Ingestion & $1.01 \mathrm{E}+13$ & $5.07 \mathrm{E}+13$ \\
\hline $\mathrm{Nb}-94$ & $3.00 \mathrm{E}+02$ & External & $4.69 \mathrm{E}+05$ & $2.35 \mathrm{E}+06$ \\
\hline Tc-99 & $3.00 \mathrm{E}+05$ & Ingestion & $9.68 \mathrm{E}+06$ & $4.84 \mathrm{E}+07$ \\
\hline Pd-107 & $3.00 \mathrm{E}+05$ & Ingestion & $3.93 \mathrm{E}+08$ & $1.97 \mathrm{E}+09$ \\
\hline $\mathrm{Sn}-121 \mathrm{~m}$ & $3.00 \mathrm{E}+04$ & Ingestion & $1.96 \mathrm{E}+10$ & $9.81 \mathrm{E}+10$ \\
\hline Sn-126 & $3.00 \mathrm{E}+03$ & External & $4.03 \mathrm{E}+05$ & $2.02 \mathrm{E}+06$ \\
\hline I-129 & $3.00 \mathrm{E}+04$ & Ingestion & $6.34 \mathrm{E}+04$ & $3.17 \mathrm{E}+05$ \\
\hline Cs-135 & $3.00 \mathrm{E}+04$ & Ingestion & $8.59 \mathrm{E}+06$ & $4.29 \mathrm{E}+07$ \\
\hline Cs-137 & $3.00 \mathrm{E}+02$ & Ingestion & $2.41 \mathrm{E}+11$ & $1.20 \mathrm{E}+12$ \\
\hline Sm-147 & $3.00 \mathrm{E}+02$ & Inhalation & $1.81 \mathrm{E}+05$ & $9.05 \mathrm{E}+05$ \\
\hline Sm-151 & $3.00 \mathrm{E}+05$ & Inhalation & $9.03 \mathrm{E}+10$ & $4.52 \mathrm{E}+11$ \\
\hline $\mathrm{Pb}-210$ & $3.00 \mathrm{E}+02$ & Ingestion & $7.01 \mathrm{E}+08$ & $3.50 \mathrm{E}+09$ \\
\hline Ra-226 & $3.00 \mathrm{E}+02$ & Ingestion & $7.15 \mathrm{E}+05$ & $3.57 \mathrm{E}+06$ \\
\hline Ac-227 & $3.00 \mathrm{E}+02$ & Inhalation & $5.00 \mathrm{E}+10$ & $2.50 \mathrm{E}+11$ \\
\hline Th-229 & $3.00 \mathrm{E}+02$ & Inhalation & $3.87 \mathrm{E}+04$ & $1.94 \mathrm{E}+05$ \\
\hline Th-230 & $3.00 \mathrm{E}+02$ & Inhalation & $6.77 \mathrm{E}+04$ & $3.39 \mathrm{E}+05$ \\
\hline $\mathrm{Pa}-231$ & $3.00 \mathrm{E}+02$ & Inhalation & $1.24 \mathrm{E}+04$ & $6.22 \mathrm{E}+04$ \\
\hline Th-232 & $3.00 \mathrm{E}+02$ & Inhalation & $6.18 \mathrm{E}+04$ & $3.09 \mathrm{E}+05$ \\
\hline U-233 & $3.00 \mathrm{E}+03$ & Ingestion & $4.49 \mathrm{E}+05$ & $2.25 \mathrm{E}+06$ \\
\hline U-234 & $3.00 \mathrm{E}+02$ & Ingestion & $4.58 \mathrm{E}+05$ & $2.29 \mathrm{E}+06$ \\
\hline U-235 & $3.00 \mathrm{E}+02$ & Ingestion & $4.86 \mathrm{E}+05$ & $2.43 \mathrm{E}+06$ \\
\hline U-236 & $3.00 \mathrm{E}+03$ & Ingestion & $4.57 \mathrm{E}+05$ & $2.28 \mathrm{E}+06$ \\
\hline $\mathrm{Np}-237$ & $3.00 \mathrm{E}+02$ & Ingestion & $1.02 \mathrm{E}+05$ & $5.08 \mathrm{E}+05$ \\
\hline $\mathrm{Pu}-238$ & $3.00 \mathrm{E}+02$ & Inhalation & $1.41 \mathrm{E}+09$ & $7.03 \mathrm{E}+09$ \\
\hline U-238 & $3.00 \mathrm{E}+02$ & Ingestion & $5.08 \mathrm{E}+05$ & $2.54 \mathrm{E}+06$ \\
\hline $\mathrm{Pu}-239$ & $3.00 \mathrm{E}+02$ & Inhalation & $4.28 \mathrm{E}+04$ & $2.14 \mathrm{E}+05$ \\
\hline $\mathrm{Pu}-240$ & $3.00 \mathrm{E}+02$ & Inhalation & $5.32 \mathrm{E}+04$ & $2.66 \mathrm{E}+05$ \\
\hline Am-241 & $3.00 \mathrm{E}+02$ & Inhalation & $8.26 \mathrm{E}+06$ & $4.13 E+07$ \\
\hline $\mathrm{Cm}-244$ & $3.00 \mathrm{E}+02$ & Inhalation & $1.68 \mathrm{E}+21$ & $8.38 \mathrm{E}+21$ \\
\hline
\end{tabular}

From the Table 1 is clear that the radiation impact of Scenario S5 is negligible in the long time scale. Results of other scenarios are very similar. Recalculated specific activities of some radionuclides (Co-60, Nb-93m, etc.) reach very high values comparing to the legislation. In case of these radionuclides it is expected that they will be limited in short-term, for example during melting process or building of construction [7]. Mentioned processes are out of scope of this paper. Generally it is possible to say that levels of specific activities of chosen radionuclides could be increased by one or more orders of magnitude (towards legislation) keeping required safety standards - annual individual effective dose $10 \mu \mathrm{Sv}(50 \mu \mathrm{Sv})$ and annual collective effective dose 1 man Sv.

\section{Conclusion}

Results of calculations show that the concept of conditional clearance of materials reused in building industry represents no significant safety issue in long-term. Clearance levels could be increased compared to legislation criteria for unconditional clearance. This fact leads to bigger share of recycled materials in the material flow of the decommissioning of NI. More recycled materials represent more saved financial funds, more saved repository capacities and last but not least more saved mineral resources.

\section{Acknowledgements}

This project has been partially supported by the Slovak Grant Agency for Science through the grants No. VEGA 1/0685/09, VEGA 1/0796/13 and by the Ministry of Education by decree No. CD-2009-36909/39460-1:11 within the bounds of project CONRELMAT.

\section{References}

[1] GoldSim Technology Group, GoldSim Users Guide, (2010).

[2] International Atomic Energy Agency, Application of the concepts of exclusion, exemption and clearance, IAEA SSS No. RS-G-1.7, (2004).

[3] International Atomic Energy Agency, Derivation of activity limits for the disposal of radioactive waste in near surface disposal facilities, IAEA-TECDOC-1380, (2001).

[4] European Commission, Practical use of the concepts of clearance and exemption, RP 122, (2000).

[5] International Commission on Radiological Protection, Nuclear decay data for dosimetric calculations, ICRP - 107, (2008).

[6] International Atomic Energy Agency, Handbook of parameter values for the prediction of radionuclide transfer in terrestrial and freshwater environments, IAEA-TRS-472, (2010).

[7] T. Hrncir and V. Necas, Radiation impact of very low level radioactive steel reused in motorway tunnel constructions, Progress in Nuclear Science and Technology, (2013). 